\title{
NARRATIVAS DE EMPREENDEDORES SOCIAIS PORTUGUESES E BRASILEIROS: PERCURSOS DE VIDA E PROJETOS DE TRANSFORMAÇÃO ${ }^{1}$
}

NARRATIVES OF PORTUGUESE AND BRAZILIAN SOCIAL ENTREPRENEURS: LIFE COURSES AND TRANSFORMATION PROJECTS

\author{
Vander Casaqui
Professor do Programa de Pós-Graduação em Comunicação e Práticas de Consumo - \\ PPGCOM ESPM. Doutor em Ciências da Comunicação pela Universidade de São Paulo, \\ com Pós-doutorado pela FCSH-Universidade Nova de Lisboa. vcasaqui@hotmail.com
}

Recebido em 30 de abril de 2014. Aprovado em 25 de agosto de 2014

\section{Resumo}

Este trabalho trata do tema do empreendedorismo social em perspectiva comparativa, dos contextos brasileiro e português. Analisamos, a partir de entrevistas em profundidade, as trajetórias de vida narradas de empreendedores sociais portugueses e brasileiros, relacionando-as com os significados de seu papel social (Dahrendorf, 2012). A pesquisa tem como base a noção da vida como narração (Arfuch, 2010), e os estudos dos percursos de vida (Giele e Elder Jr, 1998), para analisar as narrativas de empreendedores sociais, como construções comunicacionais interdependentes do contexto e do espírito do tempo.

Palavras-chave: Comunicação; narrativas orais; empreendedorismo social.

\section{Abstract}

This article deals with the theme of social entrepreneurship in comparative perspective, between Brazilian and Portuguese contexts. We analyze, from in-depth interviews, the life courses narrated by Portuguese and Brazilian social entrepreneurs, relating them to the meanings of their social role (Dahrendorf, 2012). The research is based on the notion of life as narration (Arfuch, 2010), and on studies of life courses (Giele and Elder Jr, 1998), to analyze the narratives of social entrepreneurs, as communicational constructs interdependent of context and spirit of time.

Keywords: Communication; oral narratives; social entrepreneurship.

1 Versão revista do trabalho apresentado no II Congresso Mundial de Comunicação Ibero-Americana Confibercom, realizado na Universidade do Minho, Braga, Portugal, entre 13 e 16 de abril de 2014.

$$
\frac{\text { Comunicação \& Inovação, PPGCOM/USCS }}{\text { v. 15, n. } 29 \text { (95-105) jul-dez 2014 }} 95
$$




\section{Introdução}

A pesquisa que desenvolvemos com empreendedores sociais, apresentada parcialmente neste artigo, tem como enfoque sua dimensão comunicacional, ou seja, a construção do eu como vida narrada, a partir da situação de entrevista. Diante da cena enunciativa em que o agente social é instigado a traduzir em linguagem a sua experiência de trabalho, suas práticas de consumo, suas memórias e ideais, suas leituras do contexto de seus países e do campo em que atuam, buscamos compreender como o espírito do tempo se relaciona com a subjetividade.

Por meio desses enunciados de empreendedores sociais temos acesso ao mundo editado pela linguagem, às visões de mundo, aos códigos hegemônicos que atravessam as falas dos sujeitos em suas posições sociais e às negociações que são feitas por meio das manifestações da subjetividade. Nas vozes que constituem uma comunidade imaginada (ANDERSON, 2005) percebemos como se estrutura a lógica de um campo de atuação (Bourdieu, 2003), entre sentidos universalizantes e demarcações de vinculações locais.

Mair, Robinson e Rockerts (2006, p. 1) indicam que o conceito de empreendedorismo social é, na prática, reconhecido por abranger um vasto leque de atividades, da ação de sujeitos empreendedores devotados a causas sociais, a modelos de negócios aplicados ao terceiro setor, em que o mercado ora é visto como inspiração, ora como fonte de recursos para a chamada "sustentabilidade" dos projetos sem fins lucrativos. De acordo com a leitura do espírito do capitalismo contemporâneo (BOLTANSKI \& Chiapello, 2009), o empreendedorismo social é visto neste trabalho como forma de engajamento no sistema, gerador de vinculação e motivação para novos quadros, na renovação da retórica capitalista que ecoa o ideário revolucionário da geração de maio de 1968, associando esse ideário com a atividade empreendedora com vistas ao "bem comum". Nesse sentido, a atuação do empreendedor social, pelos discursos que alimentam os significados de seu papel social (DAHRENDORF, 2012), ganha contornos heroicos: o chamado changemaker, como denomina a organização Ashoka (uma das principais incentivadoras da cena empreendedora social global), é um sujeito que assume uma missão, que é visionário e determinado, que é capaz de mudar o mundo, por mais que esse espírito revolucionário que o cerca esteja condicionado à necessidade de ser "sustentável". A sustentabilidade econômica, como palavra de ordem da cena em que esse agente se situa, é determinante na forma como o modus operandi do empreendedor se sobrepõe ao idealismo e à vocação para o envolvimento com causas e problemas sociais.

$96 \frac{\text { Comunicação \& Inovação, PPGCOM/USCS }}{\text { v. 15, n. } 29 \text { (95-105) jul-dez } 2014}$ 


\section{A narração da vida e o empreendedorismo social}

No estudo comparativo entre o Brasil (cena do empreendedorismo social de São Paulo) e Portugal (agentes de Lisboa e do Porto), extraímos das vozes desses agentes sociais a forma como constroem o valor de seu trabalho e seu papel social (DAHRENDORF, 2012); como organizam a memória e articulam a história da própria vida com a atividade empreendedora com vistas ao bem comum; como diagnosticam o contexto em que vivem e seu posicionamento neste espectro; e, finalmente, como refletem sobre o futuro de seu país pela ótica de seu campo de atuação.

Leonor Arfuch (2010), em sua teoria do espaço biográfico, apresenta um diagnóstico de nosso tempo, no que se refere à exposição da experiência humana, de narrativas de vida publicizadas pelos meios técnicos disponíveis. O espaço biográfico compreende biografias e autobiografias, relatos, depoimentos, histórias de vida, enfim, exposições do eu que articulam o cotidiano, a mídia e as práticas de consumo. Diante dos meios técnicos disponíveis de hoje, palavras, imagens, materiais audiovisuais, seja na produção midiática institucionalizada, seja nas práticas cotidianas dos sujeitos, traduzem as trajetórias de vida em linguagem:

O novo traçado do espaço público transformou decisivamente os gêneros autobiográficos canônicos, aqueles que esboçavam as formas modernas de enunciação do eu. $\mathrm{O}$ avanço da midiatização e de suas tecnologias da transmissão ao vivo fez com que a palavra biográfica íntima, privada, longe de se circunscrever aos diários secretos, cartas, rascunhos, escritas elípticas, testemunhos privilegiados, estivesse disponível, até a saturação, em formatos e suportes em escala global (ARFuch, 2010, p. 151).

Nesse espectro, uma forma agrega elementos de diversos gêneros e ganha predominância nesse processo de midiatização da subjetividade: a entrevista. Sem precisão histórica, Arfuch supõe que sua emergência se deu na segunda metade do século XIX, "como maneira de resguardar e autenticar palavras ditas na imprensa" (idem). No que se refere à cena do empreendedorismo social, encontramos a presença dessa forma em um gênero que popularizou e, em certo grau, alçou à dimensão de celebridades alguns atores desse campo: o documentário. Referimo-nos especificamente ao filme Quem se importa, dirigido pela cineasta brasileira Mara Mourão e lançado em 2011. Esse filme foi o desencadeador da ideia desta pesquisa de pós-doutoramento, uma vez que, tendo me dedicado desde 2007 ao estudo das representações do mundo do trabalho na mídia, deparava-me com um fenômeno intrigante: a midiatização do empreendedor social e sua entrada em cena em um espectro mais amplo do que o seu campo de atuação. 
Este estudo se aproxima da figura do empreendedor social a partir de sua dimensão narrativa: a forma como compõe sua experiência e suas opiniões em vida narrada faz do empreendedor social um sujeito que articula, a partir de seu lugar de fala, as dimensões particulares e sociais, através dos quais procuramos compreender o espírito do tempo. Por meio de sua análise da obra de Ricoeur, Sarlo (2007, p. 49) afirma que "a hegemonia do presente sobre o passado no discurso é da ordem da experiência e se apoia, no caso do testemunho, na memória e na subjetividade”. Dessa forma, passado e presente - e por que não, as projeções futuras - estão inevitavelmente ligados à subjetividade presente em seus condicionantes, suas premissas e sua situação de fala. O empreendedor social é um sujeito que une as especificidades de sua experiência particular com a vivência de um papel significado socialmente, a partir do qual rearticula a memória, faz diagnósticos da situação presente e lança olhares para um futuro que considera possível: "fala-se do passado sem suspender o presente e, muitas vezes, implicando também o futuro" (ibid., p. 12).

Bourdieu (1996, p. 184) defende a ideia de que a biografia é uma ilusão, uma vez que "o relato autobiográfico se baseia sempre, ou pelo menos em parte, na preocupação de dar sentido, de tornar razoável, de extrair uma lógica ao mesmo tempo retrospectiva e prospectiva", de dar uma ordenação, relações de causa e efeito, etapas e progressões, objetivos norteadores, entre outros recursos narrativos para tratar da própria vida. Ao reconstruir fragmentos da memória, opiniões, objetivos e pertencimento a uma noção de coletividade, o empreendedor social, mais do que expor "a vida como ela é", evidencia regras, lógicas sociais, regulações morais, visões de mundo em circulação no tempo e no espaço em que se situa, uma vez que

O mundo social, que tende a identificar a normalidade com a identidade entendida como constância em si mesmo de um ser responsável, isto é, previsível ou, no mínimo, inteligível, à maneira de uma história bem construída (...), dispõe de todo tipo de instituições de totalização e de unificação do eu (Bourdieu, ibid., p. 186).

Nesse sentido, a totalização do eu que serve de objeto a este estudo é a figura do empreendedor social, como agente que corresponde a uma posição e a um papel social (DAHRENDORF, 2012). O autor faz a distinção entre os dois termos: a posição corresponde a um lugar numa hierarquia estabelecida, reconhecida em uma estrutura, a partir de uma institucionalidade; o papel social aproxima este ator aos valores que lhe são atribuídos em um circuito social mais amplo, em diálogo com as representações e os imaginários que lhe dão significado. Essa constituição como papel social dá ao empreendedor social a dimensão que interessa a nossa pesquisa, pois se refere à maneira como o espírito do tempo, as 
questões culturais, o ambiente de dado momento histórico e os contextos que o abrigam operam para caracterizar seu sentido. Em outras palavras: a denominação empreendedor social pode remeter a uma ideia universalizante, a um sujeito (simultaneamente individual e coletivo) que agrega atribuições técnicas ajustadas à economia de mercado capitalista, uma condição moral voltada ao trabalho pelo "bem comum", uma conjunção de eficácia operacional com a benevolência que anteriormente era creditada aos caridosos, aos "bons de coração", aos sujeitos que defendem os princípios humanistas. No entanto, mesmo que o empreendedor social tenha um perfil reconhecido em diversos contextos, é por meio de suas peculiaridades, de suas características específicas em dada cultura, que ficam evidenciadas as dinâmicas discursivas que agem em sua construção.

Um dos fatores que afetam a configuração do papel do empreendedor social, evidentemente, é a ação das lógicas de seu campo (BOURDIEU, 2003), que tensiona a manifestação das subjetividades em narrativas que guardam certo grau de compartilhamento de valores, ideias, objetivos e sonhos. O reconhecimento dos pares, a repercussão positiva de suas ações para a sociedade, as consagrações materializadas em premiações, em concessão de espaços privilegiados de fala, em apoios obtidos para projetos e iniciativas, apontam para aqueles empreendedores exemplares na cena de sua região, de seu país, e para além deles.

Bourdieu é preciso na leitura da relação entre individualidade e institucionalidades, entre o que é identificado com a particularidade subjetiva e aquilo que corresponde ao espaço social ocupado pelo sujeito:

Tentar compreender uma vida como uma série única e por si suficiente de acontecimentos sucessivos, sem outro vínculo que não a associação a um "sujeito" cuja constância certamente não é senão aquela de um nome próprio, é quase tão absurdo quanto tentar explicar a razão de um trajeto do metrô sem levar em conta a estrutura da rede, isto é, a matriz da relações objetivas entre as diferentes estações (1996, pp. 189-190).

$\mathrm{Na}$ direção apontada por Bourdieu, compreendemos o entrelaçamento da vida e das experiências individuais com seu contexto, com os cenários que lhe dão sentido. Esse trânsito entre o âmbito individual e a esfera social permite inscrever os relatos como documentos históricos construídos em uma situação de entrevista, na qual os fragmentos de memória, percepções do presente e projeções futuras que se conjugam com um espírito do tempo. Segundo Bertaux (2005, p. 36), sempre há relato de vida a partir do momento em que "um sujeito conta a outra pessoa, investigador ou não, um episódio qualquer de sua experiência vivida. O verbo "contar” (narrar) aqui é essencial: significa que a produção 
discursiva do sujeito adotou uma forma narrativa" (tradução nossa). A experiência narrada, em nossa pesquisa, refere-se à articulação da vida com o papel do empreendedor social, que serve como eixo organizador da transição entre os acontecimentos passados, as reflexões sobre a cena atual e o olhar para um possível futuro.

\section{Análise das narrativas de empreendedores sociais}

Diante do considerável grau de polissemia no que tange à conceituação do empreendedor social, optamos por fazer valer a lógica do campo na identificação dos agentes a serem incorporados à pesquisa, para realização das 21 entrevistas, 10 entre Lisboa e Porto e 11 na cidade de São Paulo. Em termos práticos, essa opção levou primeiramente a uma imersão na cena portuguesa durante o período de realização do estágio pós-doutoral, sediado na Universidade Nova de Lisboa. O ponto de partida para o reconhecimento dos agentes tidos como exemplares da cena empreendedora social da cidade foi o evento Job Party, voltado a estudantes universitários portugueses, que foi realizado nas principais instituições do país durante o primeiro semestre de 2013. Na programação da "Festa do Trabalho", o trabalho, escasso em tempos de crise em Portugal, especialmente de primeiro emprego para jovens, dá lugar ao empreendedorismo - o "autoemprego" - e ao empreendedorismo social. Dividido em blocos, o evento reservava uma sessão à apresentação de projetos de empreendedores sociais bem-sucedidos, relatando suas trajetórias para "inspirar" os estudantes diante dos reflexos da crise no mercado de trabalho. A maioria absoluta dos entrevistados em Lisboa ocupou esse espaço reservado às histórias exemplares de empreendimentos sociais.

Outro espaço representativo do campo do empreendedorismo social em Portugal é o IES - Instituto de Empreendedorismo Social, cuja plataforma digital coloca em evidência os empreendimentos sociais de excelência, segundo seus padrões de qualidade. Instituições da cidade do Porto que receberam essa distinção foram contatadas para fazer parte da pesquisa. O Mapa de Inovação e Empreendedorismo Social (MIES), iniciativa do IES em colaboração com o Instituto Padre Antônio Vieira (IPAV), tem se dedicado a mapear e divulgar as iniciativas exemplares no território português.

Na cidade de São Paulo, uma das principais referências foi o Prêmio Empreendedor Social do jornal Folha de São Paulo, premiação que recebe o apoio da Fundação Schwab, uma das mais notórias instituições de incentivo ao empreendedorismo social no mundo. Plataformas de divulgação de projetos como a rede Atados (www.atados.com.br), assim como o Projeto Imagina na Copa (imaginanacopa.com.br), serviram de ponto de partida para localizarmos empreendedores sociais de destaque e reconhecimento na cena contemporânea paulistana.

$100 \frac{\text { Comunicação \& Inovação, PPGCOM/USCS }}{\text { v. 15, n. } 29 \text { (95-105) jul-dez } 2014}$ 
O estudo dos percursos ou trajetórias de vida, de acordo com Giele e Elder Jr. (1998), é baseado na leitura da articulação de quatro elementos, a saber:

1. Localização no tempo e no espaço (location in time and place);

2. Vidas interligadas (linked lives);

3. Orientação pessoal das ações (human agency);

4. Momentos da vida (timing of lives).

Esses elementos se articulam na narrativa de vida, construída na situação de entrevista, em que os sujeitos, abordados como empreendedores sociais, dão sentido à experiência vivida, às próprias opiniões, às leituras do campo onde se situam e do contexto socioeconômico que os abriga. Passado, presente e futuro são alinhavados na trama da vida narrada a partir da construção de um cenário delimitado pelo tempo e pelo espaço (location in time and place); das relações sociais, indispensáveis na caracterização da experiência e da identidade (linked lives); das manifestações da subjetividade e da especificidade do eu (human agency); e, por fim, dos ciclos, das etapas da vida em perspectiva diacrônica, acoplando os diversos tempos e modos de estar no mundo (timing of lives).

Em relação à localização (item 1), o momento econômico, social de cada país é evidenciado em meio ao desenvolvimento da reflexão sobre o próprio trabalho e sobre a situação do empreendedorismo social. No contexto português, a crise é um termo onipresente, caracterizando-se para além das dificuldades econômicas ou da esfera política, ou por consequência delas, como podemos perceber pelo trecho da entrevista com uma empreendedora social da cidade do Porto:

Sem eles, sem os empreendedores sociais, infelizmente... e com a degradação do Estado Social em Portugal, com a degradação até, se calhar, da confiança da sociedade, se não houver quem impulsione aqui uma mudança, que crie novas estruturas, que crie novas respostas, novas estratégias, iríamos, eu acho que vamos regredir no tempo.

As entrevistas em Portugal, realizadas no mês de abril de 2013, coincidiram com um momento de elevada crise, e com manifestações contrárias às políticas de austeridade assumidas pelo governo, acirradas com a proximidade do aniversário da revolução de 25 de abril de 1974, que marcou o início da reabertura democrática de Portugal após décadas de ditadura salazarista. De forma geral, a presença do Estado Social, enfraquecido com a crise, tomou parte do diagnóstico dos problemas ou do cenário a partir do qual o empreendedor desenvolve sua atividade; no entanto, ele se apresenta oculto quando o exercício 
de pensar o futuro do país é colocado. Pensar Portugal daqui a 10 anos é pensar em um país no qual o Estado não é considerado como parte da solução dos problemas; essa tarefa é delegada ao empreendedor social. Em todos os casos, tanto em Portugal quanto no Brasil, a projeção do cenário de 10 anos à frente, sem que haja empreendedorismo social, convergiu para o mesmo sentido; a visão comum é a de que a ausência da atividade do empreendedor social representa uma piora significativa da situação do país, quando não há alusão ao caos, à tragédia social ou à falência absoluta da nação.

As entrevistas realizadas no Brasil, no mês de agosto de 2013, tiveram como pano de fundo o ambiente ainda recente das jornadas de junho - as manifestações que tomaram as ruas do país e que expuseram a crise da representação política. Esse momento surge em dois sentidos opostos: tanto aparece como um estímulo à euforia, à crença em uma mudança social em curso e à mobilização dos cidadãos, quanto é interpretado como exemplo de um comportamento negativo a ser transformado em relação aos brasileiros. As críticas de alguns empreendedores sociais caminham na direção da ausência de engajamento na política tradicional, de apoio ativo a projetos sociais, da "reclamação" sem propostas claras. Percebemos que a pauta midiática daquele momento histórico, mesmo não tendo sido colocada diretamente em questão, fez-se presente na organização do raciocínio dos empreendedores sociais sobre o país e seu futuro.

Uma recorrência que parece atravessar fronteiras, pois está presente nos dois grupos de entrevistas, é a caracterização de um perfil do empreendedor social que corresponde a uma ética, a um estilo de vida específico. Dessa forma, tanto portugueses quanto brasileiros concordam, guardadas algumas nuances, em apontar que o empreendedor social é aquele que é movido pela paixão, ousado, inconformado, que deve ser resiliente e persistente para atuar no que acredita; que tem de renunciar a uma vida estável e a interesses pessoais para trabalhar pelo outro, pela sociedade, para "mudar o mundo". Essa visão de mundo do empreendedor social é moldada por ao menos uma grande transformação na vida; também é recorrente em ambos os contextos à narrativa da iluminação, do esclarecimento, da missão assumida. Nesse último caso, há uma forte vinculação dessa grande transformação com a inspiração ou conexão com a religiosidade, muitas vezes em registro orientalista. A viagem de descoberta do "eu interior" também é representada pela viagem física, como no caso da empreendedora social de Lisboa que revelou ter recebido uma "missão" quando estava na Índia. A orientação pessoal das ações (item 3) se expressa a partir dessa noção de uma narrativa terapêutica aos moldes das análises de Illouz (2011), ou seja: o passado é visto como patológico, como algo a ser transformado, e o estado presente é o momento em que o "verdadeiro eu" está em equilíbrio, no caminho certo. Esse passado como patologia passa tanto pelo trabalho em organizações

$102 \frac{\text { Comunicação \& Inovação, PPGCOM/USCS }}{\text { v. 15, n. } 29 \text { (95-105) jul-dez } 2014}$ 
"comuns", quanto pelo comportamento "consumista" que foi modificado pelo despertar da consciência. Essa leitura do comportamento de consumo como conflitante com a ética empreendedora social evidencia o seu conflito com a noção de "sustentabilidade"; apesar de terem gostos comuns, como sair para jantar, dançar, ouvir música, comprar livros e outras mercadorias, a primeira reação ao questionamento é a negação das próprias práticas de consumo, talvez lidas como incompatíveis com um estilo de "vida sustentável".

No mesmo sentido, a trajetória de vida mobilizada pela memória da infância (relacionada ao item 4), constitui um percurso que vai dessa etapa da vida ao momento atual, da experiência na idade adulta, em que o sujeito passou pela revelação de uma grande transformação. Ou seja: interpelado pelo exercício de recordar de um momento do passado, parte dos empreendedores sociais, tanto portugueses quanto brasileiros, encontraram em fragmentos da existência passada a vocação para o empreendedorismo social. Como o empreendedor social de Lisboa que estabeleceu relação entre o ato de superar o medo de andar de bicicleta somente em duas rodas, sem as rodas de apoio, com a determinação para conseguir o que se quer e a autonomia para empreender. Ou como a empreendedora que viveu a infância na zona rural do interior de Portugal, em meio à natureza e cuidando de animais, que cresceu e está à frente de um projeto baseado em cooperativas agrícolas e na permacultura. Um espírito "empreendedor de si mesmo" se revela indissociável do perfil do empreendedor social. Essa característica foi bastante destacada entre os agentes portugueses entrevistados.

As vidas interligadas (item 2) são elementos fundamentais nas narrativas dos empreendedores sociais dos dois países, a partir dos quais surgem diferenças fundamentais na cena de cada um. $\mathrm{O}$ espírito cooperativo, de trabalho conjunto, de compartilhamento com o outro, é inerente ao perfil do empreendedor social de maneira geral. No caso português, o papel do empreendedor social é o de articular a cena local, de compartilhar dos problemas da comunidade e mobilizar para as ações em conjunto, sem contar com o Estado Social. Há leituras paradoxais desse contexto: tanto foi apontado que o empreendedorismo social virou "moda" em Portugal, quanto a questão da invisibilidade de seus atores e suas iniciativas pelo bem comum foi colocada.

O empreendedorismo social no Brasil tem sua marca diferencial, na leitura de parte significativa dos entrevistados, exatamente no sentido das vidas interligadas; em alinhamento com o espírito do tempo e com os meios digitais disponíveis, a formação de redes de empreendedores sociais (voluntários, apoiadores) é vista com entusiasmo, algo que foi percebido de forma tímida em Portugal. Como diz um representante de uma plataforma digital que dá visibilidade a iniciativas sociais brasileiras: "Principalmente esse negócio de criar redes, contatos... a galera do Brasil, a galera do empreendedorismo 
social do Brasil é tão cheia de contatos, e todo mundo conhece todo mundo...". Trata-se de uma marca juvenil muito presente na cena empreendedora brasileira, alimentada por uma visão positiva e "pró-ativa" e uma celebração da vontade de "mudar o mundo", sem receio de assumir e jogar com as regras e os parâmetros do mercado.

No entanto, essa visão que ganha destaque no Brasil tem como contraponto uma leitura de agentes do terceiro setor com maior trajetória, que assumiram a denominação de empreendedores sociais com sua emergência recente no cenário midiático do país. Como classifica uma empreendedora com mais de 10 anos de atuação: "No nosso país, que é um país com características feudais, alguns empreendedores sociais, eles gostam de estar na mídia, né (...); outros fazem disso seu meio de vida; e outros fazem realmente uma causa de vida". Esses agentes, alguns premiados nacionalmente e reconhecidos por instituições globais como a Ashoka, revelam a dificuldade com a burocracia legal, com as armadilhas legislativas que dificultam seu trabalho e, principalmente, com a sanha corporativa de transformar o empreendedorismo social em uma estratégia para investimento na própria imagem, como uma ação de marketing.

Por fim, como (in)conclusões, fica a questão de fundo desta pesquisa, que aparece em diversos momentos das entrevistas; é nítida a onipresença do mercado na vida narrada do empreendedor social. Seja assumindo seu modus operandi, como um player consciente das regras do jogo que pretende subvertê-lo por dentro de suas entranhas; seja como alguém que vê obstáculos nessa exigência por competitividade, sustentabilidade, replicabilidade, entre outros termos que expõem essa hibridização, por vezes mal solucionada, entre "empreender" e cuidar do "social". Entre visões eufóricas e disfóricas, os empreendedores sociais persistem, engajando-se, queiram ou não, no mercado capitalista, com o sonho de "revolucionar", de "mudar o mundo". Somente a perspectiva histórica permitirá compreender com exatidão qual é o papel destinado ao empreendedor social nas sociedades portuguesa e brasileira.

\section{Referências}

Anderson, Benedict. Comunidades imaginadas: reflexões sobre a origem e a expansão do nacionalismo. Lisboa: Edições 70, 2005.

ARFuCH, Leonor. O espaço biográfico: dilemas da subjetividade contemporânea. Rio de Janeiro: EdUERJ, 2010.

Bertaux, Daniel. Los relatos de vida: perspectiva etnosociológica. Barcelona: Edicions Bellaterra, 2005.

Boltanski, Luc \& Chiapello, Ève. O novo espírito do capitalismo. São Paulo: Martins Fontes, 2009.

Bourdieu, Pierre. O poder simbólico. Rio de Janeiro: Bertrand Brasil, 2003.

$104 \frac{\text { Comunicação \& Inovação, PPGCOM/USCS }}{\text { v. 15, n. } 29 \text { (95-105) jul-dez } 2014}$ 
. A ilusão biográfica. In: AMADO, Janaína; FERREIRA, Marieta de Moraes (orgs.). Usos e abusos da história oral. Rio de Janeiro: Editora da FGV, 1996, p.183-191.

DAHRENDORF, Ralf. Homo sociologicus. Lisboa: Quetzal, 2012.

EHRENBERG, Alain. O culto da performance: da aventura empreendedora à depressão nervosa. Aparecida, SP: Idéias \& Letras, 2010.

FAirclough, Norman. Discurso e mudança social. Brasília: Ed. UNB, 2001.

Giele, Janet Z., Elder Jr. \& Glen H. (eds.). Methods of life course research: qualitative and quantitative approaches. California, London: Sage, 1998.

Illouz, Eva. O amor nos tempos do capitalismo. Rio de Janeiro: Zahar, 2011.

MAIR, Johanna, RoBInson, Jeffrey \& HockerTs, Kai. Introduction. In: (eds.), Social entrepreneurship. London, New York: Palgrave Macmillan, 2006, p.1-13.

SARlo, Beatriz. Tempo passado: cultura da memória e guinada subjetiva. São Paulo: Companhia das Letras; Belo Horizonte: UFMG, 2007. 